\title{
Mandibular resection via mandibular-lip $L$ flap for the treatment of extensive multicystic Ameloblastoma
}

\author{
Edson Martins Oliveira Junior ${ }^{a}$, Pedro Dantas Segundo ${ }^{a}$, \\ Luciano Macedo Santos Silva ${ }^{a}$, Jorge Antonio Ferreira Marques ${ }^{a}$
}

Oliveira-Junior EM, Segundo PD, Silva LMS, Marques JAF. Mandibular resection via mandibular-lip L flap for the treatment of extensive multicystic Ameloblastoma. Autopsy Case Rep [Internet]. 2013;3(2):31-38. http://dx.doi. org/10.4322/acr.2013.015

\section{ABSTRACT}

Ameloblastoma is a benign odontogenic tumor accounting for $1 \%$ of all tumors of the maxilla and mandibula. The mandibula is committed in $85 \%$ of the cases. The tumor is locally invasive, able to infiltrate bone marrow spaces, without radiographic or macroscopic evidence. High recurrence rates are associated with different surgical techniques, which range from simple tumoral enucleation to extensive resections. The authors report a case of a 26-year old female patient with an 8-year history of progressive, non-tender, swelling of the left mandibular region. The intraoral examination showed that the floor of mouth was raised on the left side by a bulging along the bottom of the left mandibular vestibule as well as the lingual region. Over this area, there were ulcerated areas in the alveolar region of the molars and mucosal fenestration in the alveolar and lingual regions were present. A panoramic radiography revealed a multicystic lesion, resembling the soap-bubble shape endosseous lesion. The computed tomography revealed an expandable multicystic lesion compromising both mandibular cortices. The patient underwent a biopsy, which revealed the diagnosis of a multicystic variant of Ameloblastoma, with plexiform pattern, treated with left mandibular resection and immediate installation of a customized prosthesis. After a year of follow-up, no evidence of the tumor relapse was evidenced.

Keywords: Ameloblastoma; Odontogenic Tumors; Mandibular Injuries; Surgical Procedures, Operative; Mandibular Prothesis Implantation.

\section{INTRODUCTION}

The Ameloblastoma, a benign odontogenic neoplasia has a relative low incidence encompassing $1 \%$ of all tumors of the maxilla and the mandibula. Most cases are diagnosed between the third and fourth decades of life ${ }^{1}$, although it may be observed at any age. Gender or race predominance is not under a general consensus, even though
Rocha et al. ${ }^{2}$ showed a higher incidence among the Black men. The mandible is affected in about $85 \%$ of cases, especially in its posterior portions. The involvement of the maxilla, although uncommon, requires careful evaluation because of the risks related to recurrence near the base of the skull. ${ }^{3-5}$ By radiography, the tumor manifests as radiolucent

a Department of Oral and Maxillofacial Surgery and Traumatology - Hospital Geral Clériston Andrade - Feira de Santana/BA, Brazil.

Copyright $\odot 2013$ Autopsy and Case Reports - This is an Open Access article distributed of terms of the Creative Commons Attribution NonCommercial License (http://creativecommons.org/licenses/by/3.0/) which permits unrestricted non-commercial use, distribution, and reproduction in any médium provided article is properly cited. 
unilocular or multilocular images, resembling soapbubble or honeycomb shapes, associated or not with the expansion and disruption of the cortical bone. Displacement and dental root resorption are frequent. ${ }^{6,7}$

The histology is characterized as a benign tumor with a propensity to disfiguring growths. ${ }^{8}$ According to recent histological classification of odontogenic tumors of the World Health Organization $(\mathrm{WHO})^{9}$ there are 4 variants of Ameloblastoma with distinct histological and clinical features, namely: Solid or Multicystic Ameloblastoma; unicystic Ameloblastoma, desmoplastic Ameloblastoma and Peripheral. The Multicystic and unicystic variants are the most prevalent variants. The unicystic variant is mainly observed in younger patients. ${ }^{9,10}$

The unicystic Ameloblastoma is basically a local tumor with cystic characteristics while the multicystic variant can reach large proportions and infiltrate the surrounding tissues. ${ }^{11}$ The concept, which the unicystic variant previously considered less aggressive than the multicystic variant, was recently revised. ${ }^{12}$ Both variants were widely described as locally invasive, showing an expansive growth, easier in the cancellous bone because of its lower resistance. ${ }^{13}$ However, there are descriptions of cortical bone involvement, including the lower edge of the mandible ${ }^{11}$, as well as perineural growth.

The treatment of Ameloblastoma is controversial due to its biological behavior characterized by slow growing, locally invasiveness, and high rates of recurrence. Several authors have described that the multicystic variant has a higher rate of recurrence compared with the unicystic variant. ${ }^{10,14,15}$ This observation should be considered in the surgical planning.

\section{CASE REPORT}

A 26-year old female patient sought the Oral and Maxillofacial Surgery and Traumatology Department complaining of progressive, non-tender, swelling of the left mandibular region during the last 8 years. Except for the facial asymmetry, no other complaint was referred. The external examination revealed a large volumetric asymmetry consisted by a large firm swelling disfiguring the left mandibular region. No regional lymphadenopathy was palpable over the neck (Figures $1 \mathrm{~A}$ and $1 \mathrm{~B}$ ). There was no trismus or any impairment for mouth opening, and the patient had a satisfactory occlusion (Figure 1C). The intraoral examination showed a bulging mass rising from the floor of the mouth, throughout the bottom of the left mandibular vestibule as well as of the lingual region, with ulcerated areas in the alveolar region of the molars and mucosal fenestration over the alveolar and lingual regions (Figure 2).

The panoramic radiography revealed multicystic soap-bubble shape endosseous mandibular lesions with expansion to the cortical of the base of the body and angle of the left mandibula and deformation of the latter, with the inclusion of the 37 th dental element. The tumor partially surrounded the $36^{\text {th }}$ dental element, which showed a radicular resorption (Figure 3). The Computed tomography

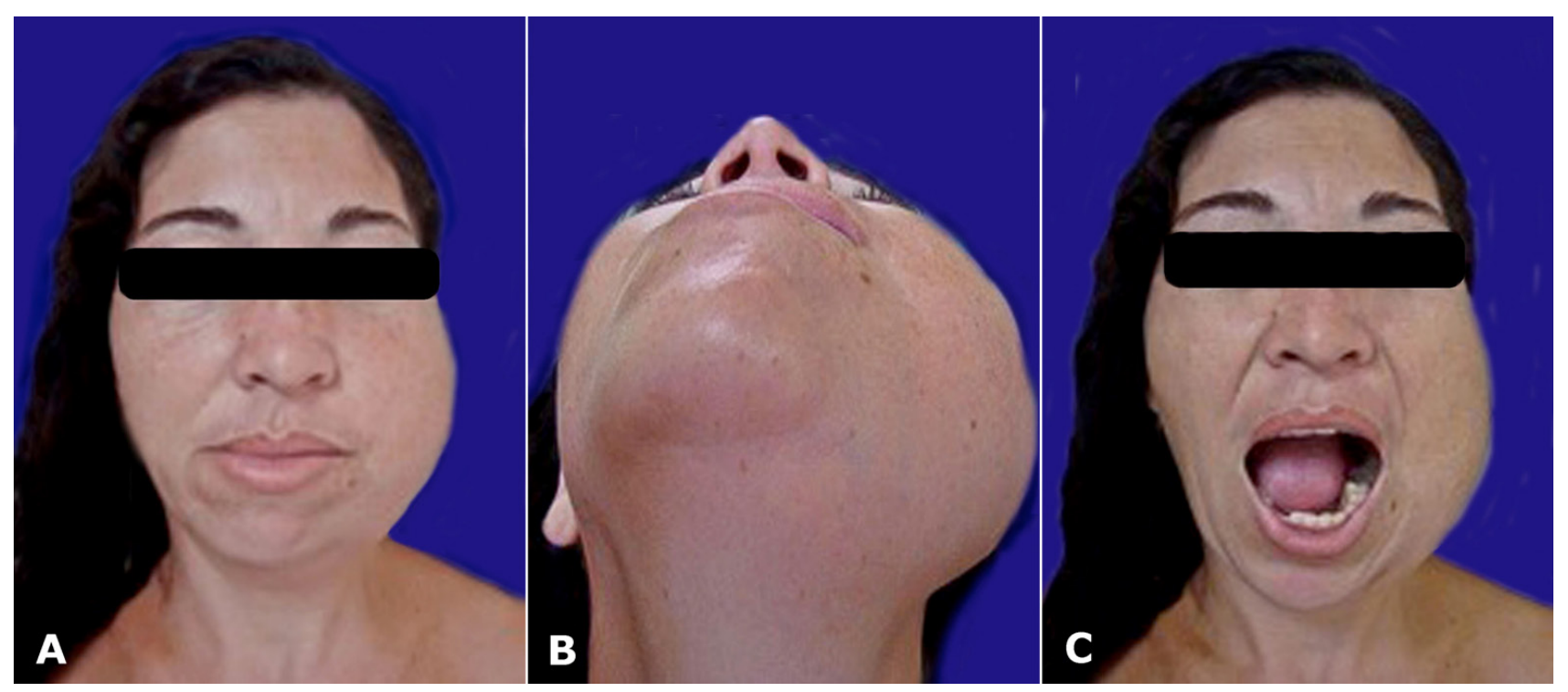

Figure 1 - A, B and C - External examination, showing facial asymmetry, due to a bulging mass in the topography of the left mandibula without causing impairment to the complete mouth aperture. 
revealed an expansive multicystic lesion drilling both cortices of the mandible, extending along the entire left mandible from the condyle to parasymphysis, measuring approximately $5 \times 1.1 \times 3.75 \mathrm{~cm}$ (Figure 4).

The histological examination of an incisional biopsy, performed by intraoral access, revealed the diagnosis of plexiform Ameloblastoma without signs of malignancy.

Considering the multicystic variant with plexiform histologic pattern as well as the large

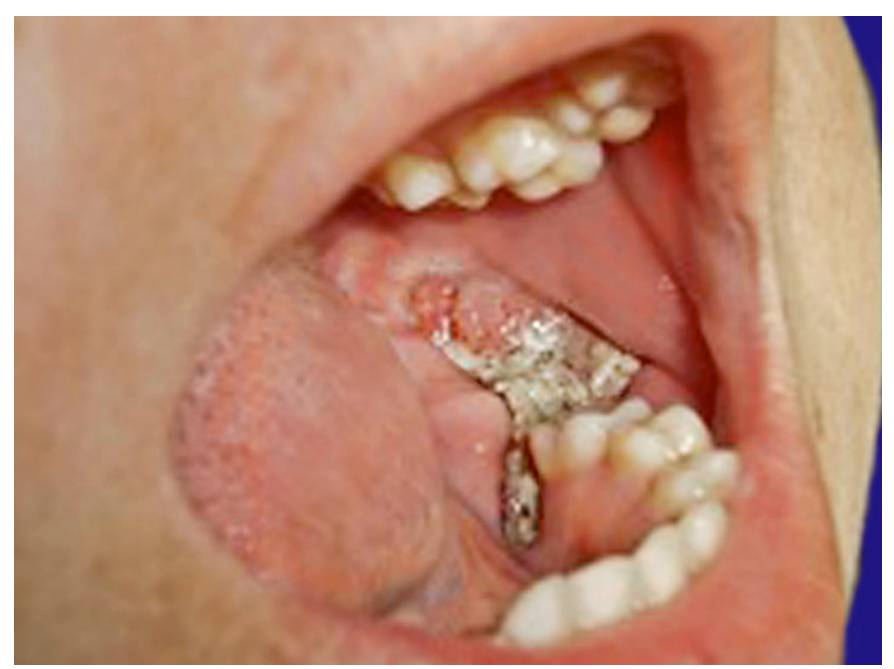

Figure 2 - Oral examination showing a destruction of the bottom of the left mandibular vestibule with ulcerated areas and mucosal fenestration over the alveolar and lingual regions. extension of the lesion, the surgical treatment consisted in left mandibulectomy with disarticulation of the left mandibular condyle followed by immediate installation of a condylar customized prosthesis made of acrylic resin coupled to a metallic reconstruction plate fixed to the mental symphisis. The surgical access was via an $L$ mandibular-labial incision with the complete tumor exposure (Figures 5, 6 and 7).

After a year of surgery and follow-up, the patient progressed with excellent mouth opening, with a slight deviation to the left, but with satisfactory masticatory function. There are no clinical nor imaging signs of recurrence (Figures 8 and 9). The control panoramic radiography after the first postoperative year is shown in Figure 10.

\section{DISCUSSION}

The treatment of Ameloblastoma still remains debatable, particularly concerning the surgical technique, rate of success versus tumor relapses and viability of adjacent anatomical structures. Ameloblastoma has great potential for recurrence if not completely removed. ${ }^{16,17}$ Different recurrence rates have been documented, depending on the surgical planning and technique, number of cases and the follow-up period. Although the reported recurrence rate of Ameloblastomas treated conservatively ranges from 75 to $90 \%$ and from 15 to $25 \%$ after radical treatment, recent

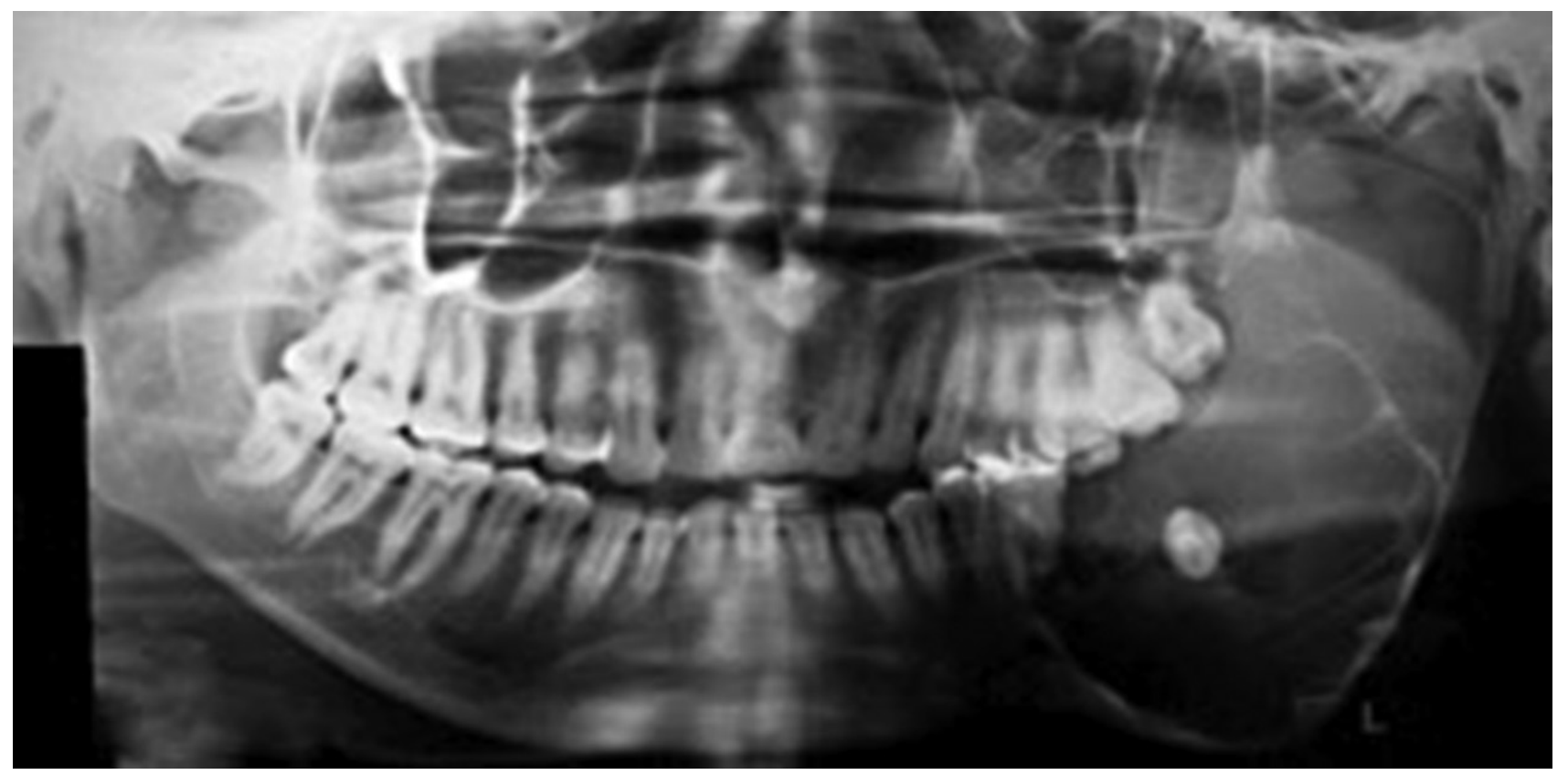

Figure 3 - Panoramic radiography showing a multicystic, soap-bubble shape endosseous mandibular lesion. Note the expansion to the cortical of the base of the body and angle of the left mandibula. 


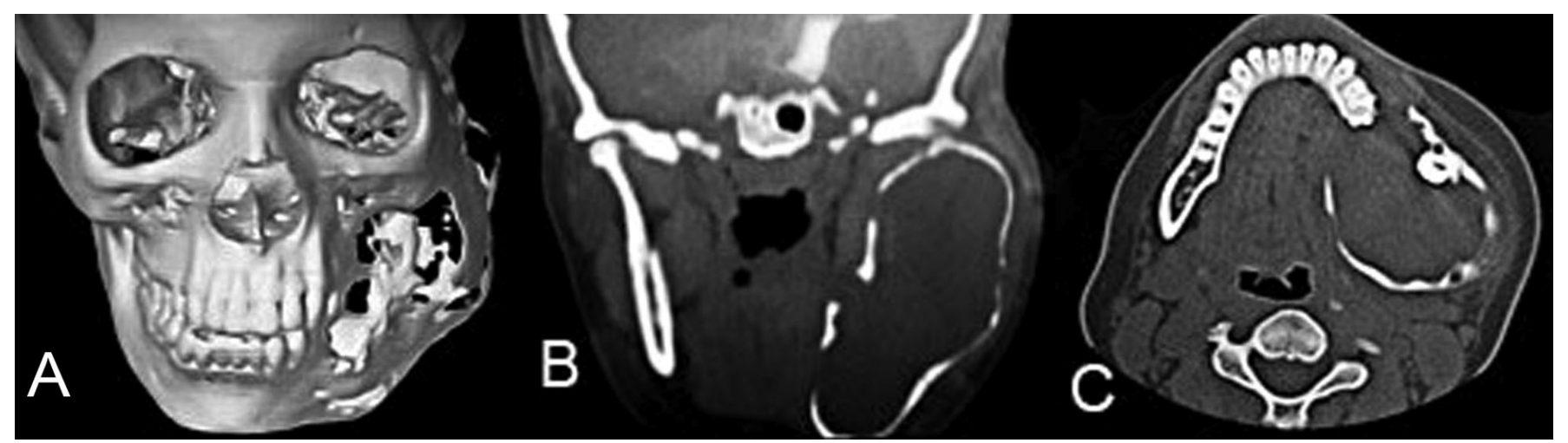

Figure 4 - Computed tomography of the face. A - Three-dimensional volumetric reconstruction of the bones of the face showing a large expansion of the left mandibula; B - Coronal plane - note the involvement of the angle, rammus and condyle of the left mandibula; $\mathbf{C}$-Axial plane - note an inclusion of a tooth within the tumoral mass.
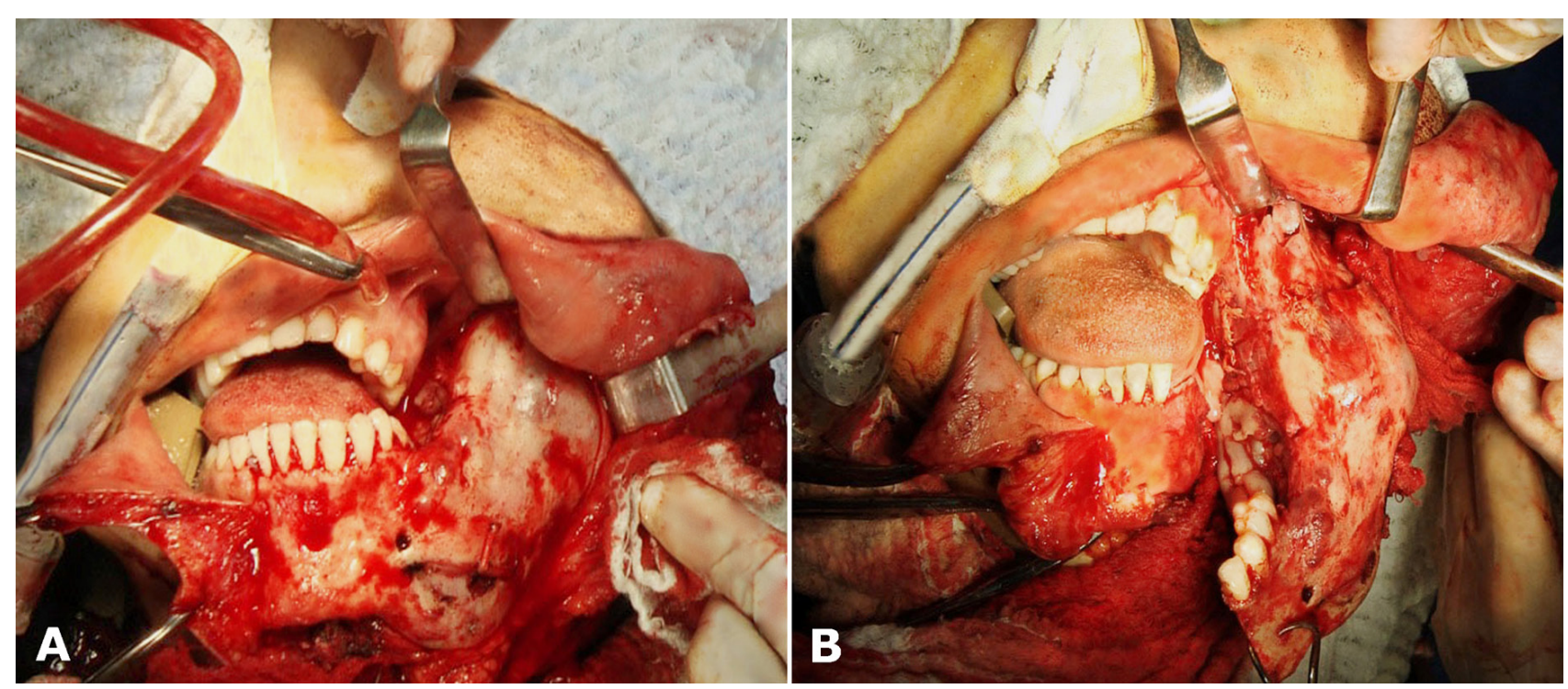

Figure 5-Panoramic view of the surgical site showing. A - L labial-mandibular Access with complete exposure of the lesion within the left mandible; B - left mandibular resection with disarticulation of the left condyle.
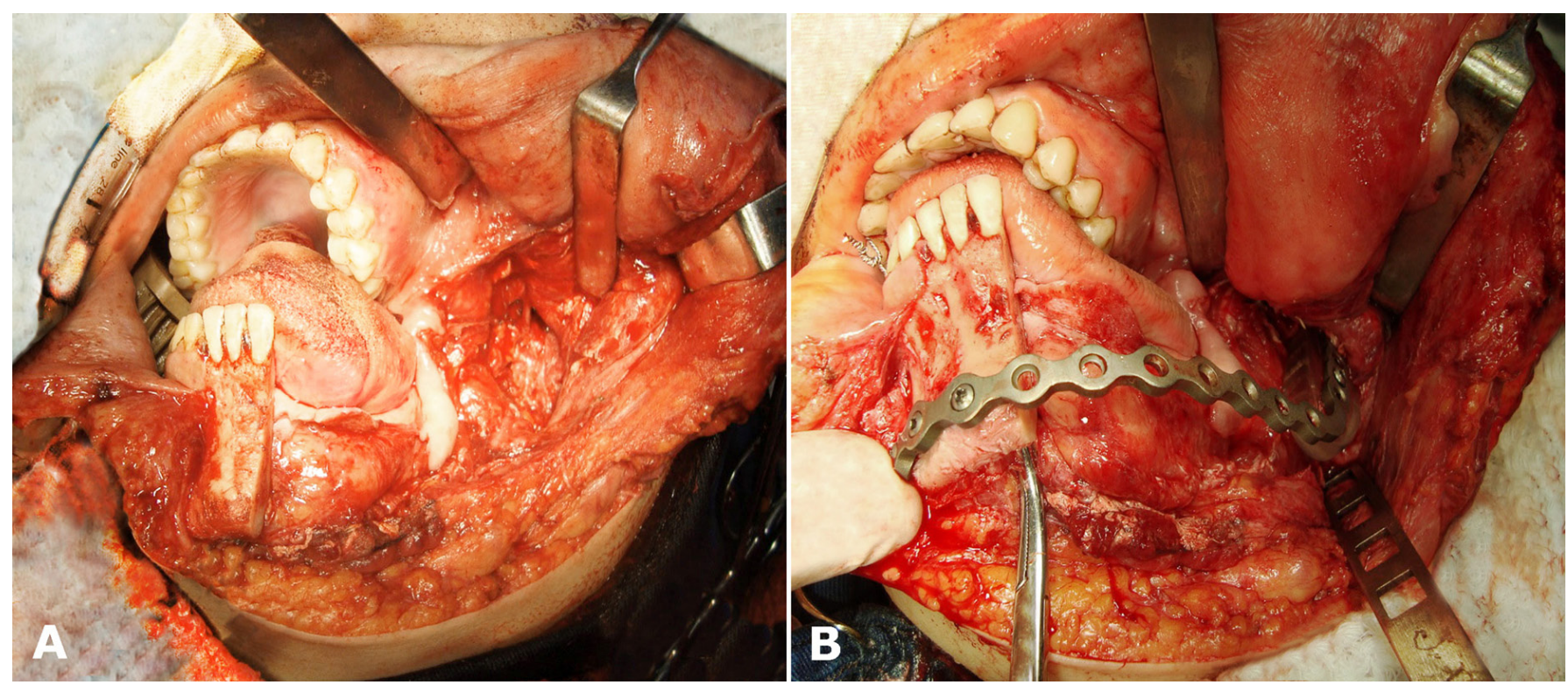

Figure 6 - A - Panoramic view of the surgical site after the left mandibulectomy and tumoral resection, BImplant of the customized prosthesis. 

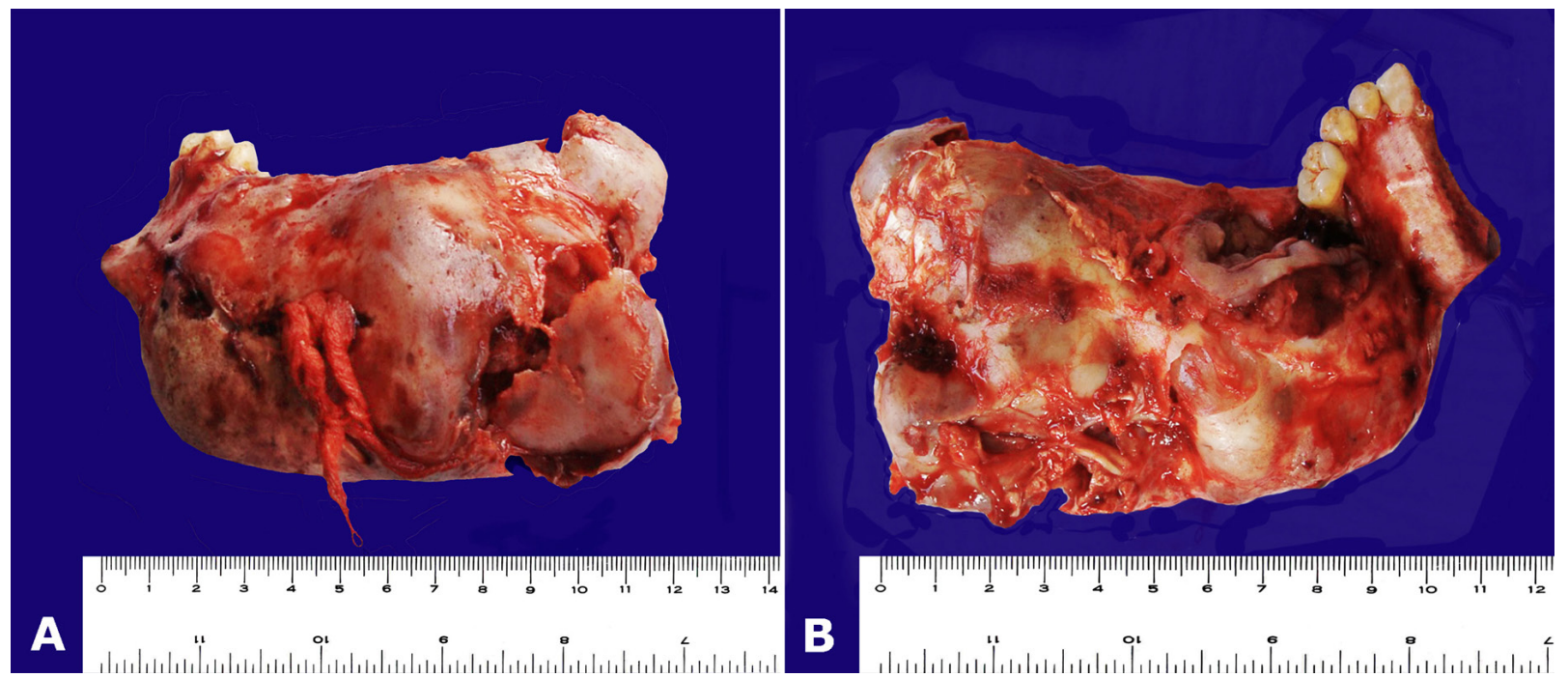

Figure 7 - A and B - Surgical specimen showing the large tumoral involvement of the mandibula, extending since the condyle to the parasynphysis.
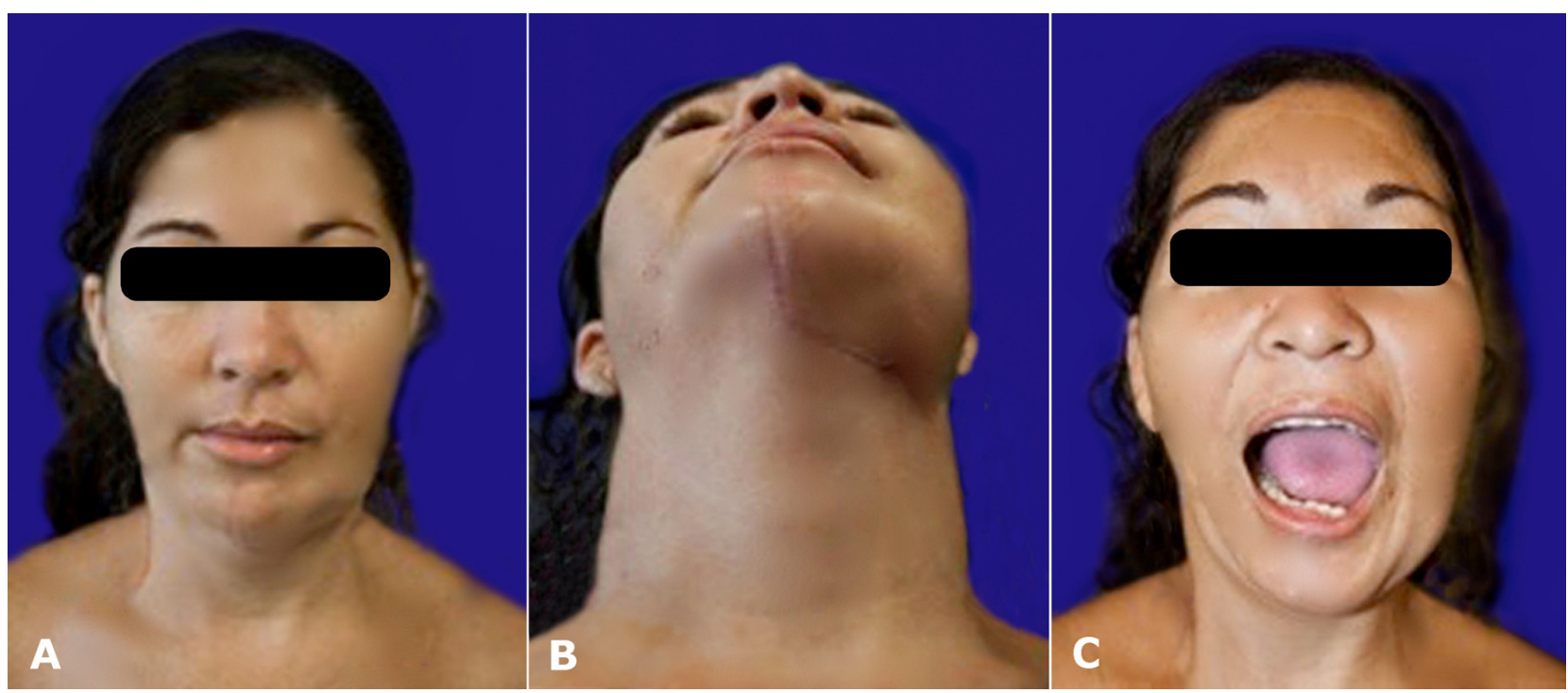

Figure 8 - External examination 1 year after the tumor resection. Note the remodeling of the facial asymmetry with the left mandibular contour maintenance and satisfactory mouth aperture and occlusion.

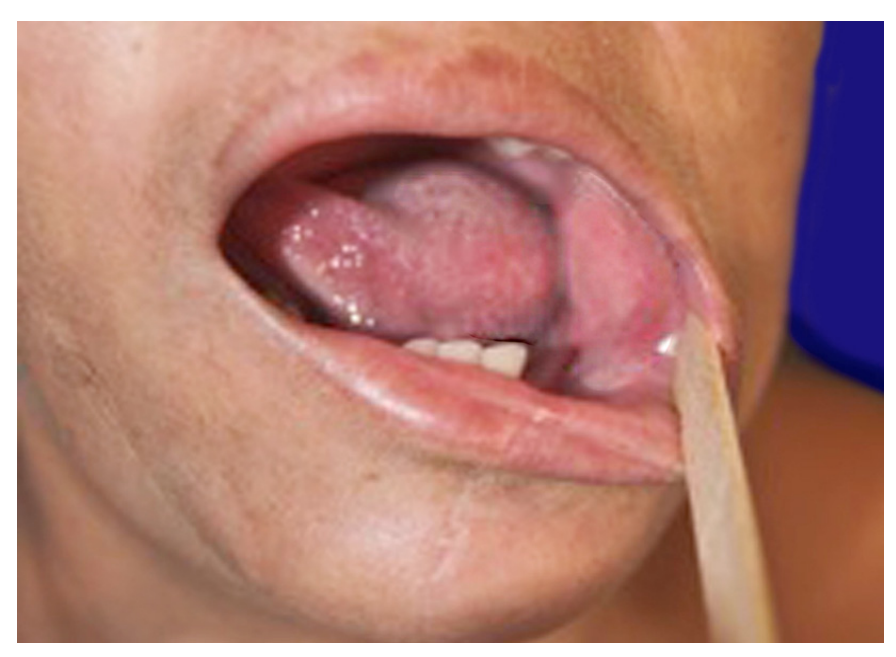

Figure 9 - Oral clinical examination 1 year after the surgery showing normal mucosa. studies showed smaller recurrence rate of $33.3 \%$ and $7.1 \%$ for those treated conservatively and radical, respectively. ${ }^{18}$ Rocha $A C^{2}$ reported a low recurrence rate observed in his study, assigning this observation to a meticulous surgical technique, what means: a) careful approach regarding soft tissue involvement, especially with the removal of peritumoral mucosa, b) extraction of teeth in contact with the lesion, c) appropriate surgical access, d) removal of the entire grossly evident tumor and e) especially thorough curettage of the surgical cavity followed by the inspection with its entire length and irregularities.

Wide resection is generally recommended for cases of follicular and plexiform Ameloblastomas 


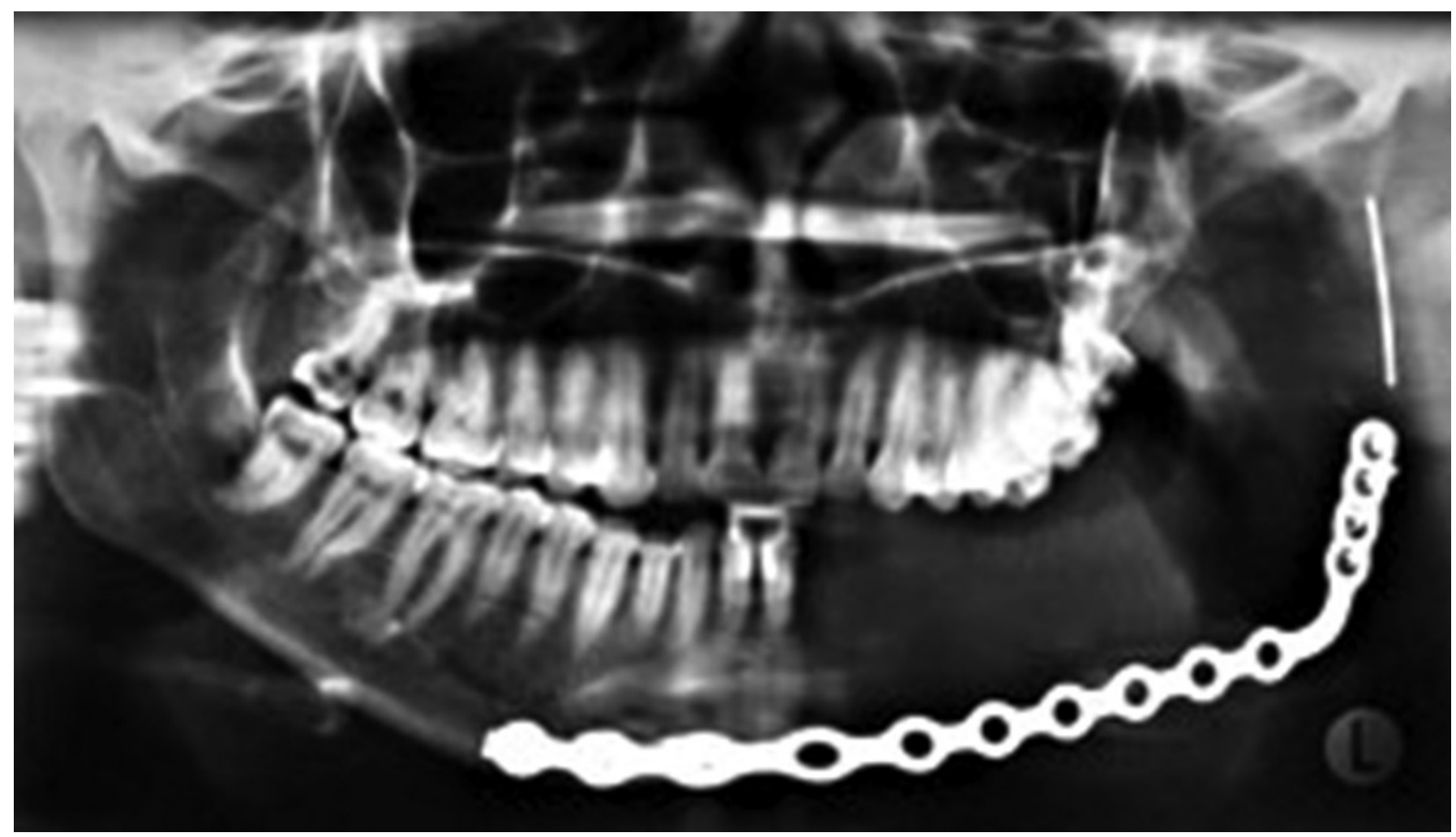

Figure 10 - Panoramic radiography obtained 1 year after the surgery, showing the well positioned customized prosthesis in the glenoid fossa and satisfactory remaining occlusion.

as well as for those with high destructive growth pattern. ${ }^{18}$ In the case of this report, the surgical staff chose left mandibular resection because of the plexiform histological diagnosis of the tumor and its extensive destructive pattern. The left mandible was almost entirely compromised by the tumor, which was completely removed by total disarticulation of the left condyle extending the resection up to the midline, respecting $2 \mathrm{~cm}$ of viable bone in order to minimize the possibility of tumoral recurrence as the current literature recommends. ${ }^{19}$

Based on histological studies on Ameloblastomas, it is recommended a surgical margin of up to $2 \mathrm{~cm}$ of normal bone, and an adequate margin of soft tissue as confirmed by frozen section when it is involved. ${ }^{11,20,21}$ Recent study showed, in cancellous bone, a maximum invasion depth of $5 \mathrm{~mm}$ from the bulk of the tumor. The same study showed the possibility of invasion of the cortical bone as well as the periosteal layer in case of expansive growth in the cortical. ${ }^{22}$ It is extremely important to remember that the border of the tumor within cancellous bone generally lies beyond the apparent macroscopic and radiographic boundaries. ${ }^{17,23}$ In the study of Gortzak et al..$^{22}$ no perforation of the periosteal layer was found, neither the surrounding tissues were invaded by the tumor. Therefore, in this study, it was suggested that the periosteal layer, in some manner, acts as a barrier against the spread of tumor cells.

In planning the surgical treatment of Ameloblastoma, the possibility of the involvement of the inferior alveolar nerve should always be considered. Nakamura et al. ${ }^{24}$ studied 22 resected mandibula in which the inferior alveolar nerve laid adjacent to, or contained within the tumor. They concluded that the preservation of the inferior alveolar nerve might be possible in the management of the unicystic type of Ameloblastoma. However, a more radical approach is necessary for treatment of multicystic or solid tumors, especially those exhibiting a follicular histological pattern. They suggested that the involvement of the inferior alveolar nerve by Ameloblastomas seems to depend on the gross appearance and histological type of tumor. Al-Khateeb et al. ${ }^{25}$, in a ten-patient series of Ameloblastoma, preserved the inferior alveolar nerve in 5 cases of radiographically unilocular tumor, and in 3 cases of multilocular tumor. In this study there was no tumor recurrence in an average 7.6-year follow-up. These authors sacrificed the inferior alveolar nerve in 2 cases where the tumor surrounded the inferior alveolar canal and its contents. Before resecting the nerve, it is recommended to isolate and remove it from its bony canal, and exam it under direct vision with magnification, particularly when the nerve has 
been displaced to the margin of the tumor. When it traverses the Ameloblastoma, the inferior alveolar nerve generally must be resected. ${ }^{26-28}$

Radical interventions are required to treat the multicystic lesions, especially those exhibiting the follicular histological pattern and when the nerve is wrapped by the tumor. ${ }^{24}$ Otherwise in some cases, the conservative treatment, comprised by marsupialization and enucleation of the tumor followed by adequate bone curettage, proved to be very efficient, reducing the need for extensive surgical resection. Tumors presenting in the early stage of development should be treated conservatively, even considering the risk of recurrence, because complications and sequelae of these surgeries are by far smaller than those caused by radical surgery. ${ }^{18}$ The conservative approach should be avoided in those cases where tumors assume large proportions; reason why the radical treatment was chosen in the case of this report.

Rocha $A C^{2}$, in his study comprising 53 cases of Ameloblastoma, treated four patients $(7.6 \%)$ by segmental mandibulectomy with surgical margin of $1.5 \mathrm{~cm}$ and disarticulation in two cases. The median follow-up was 74.2 months without evidence of tumoral recurrence. The main indication for the adopted treatment was injuries extension, which showed commitment of the cortical bone. Immediate reconstruction of the bone defect was performed with microsurgical fibular flap in three cases and reconstructive plate with acrylic condyle in one case. The main complications were: change in facial contour in all cases by improper positioning of the fibula, permanent anesthesia of the region innervated by the inferior alveolar nerve, presence of cutaneous island in the alveolar region hindering the rehabilitation and mandible deviation during mouth opening. The patient treated with a reconstructive plate presented the plate fracture nine years after the surgery, requiring its removal and reconstruction with microsurgical fibular flap. None of these patients received dental rehabilitation.

The clinical and radiographic follow-up should be as long as possible, since more than $50 \%$ of recurrences occur within 5 years after surgery. ${ }^{4,29,30}$ There are cases in which the disease recurred after 15 years of operation. 5,31,32 Periodic monitoring enables early detection of possible recurrence and their prompt treatment. To our knowledge, there is not a defined protocol for this control, but it is suggested that it should be done every six months during the first two years, annually until the tenth year and biannually from this. The case presented here presents one year of postoperative follow-up and until now no signs of recurrence were observed, neither clinically nor by imaging study

\section{REFERENCES}

1. Hughes CA, Wilson WR, Olding M. Giant ameloblastoma: report of an extreme case and description of its treatment. Ear Nose Throat J. 1999;78:568-74. PMid:10485149.

2. Rocha AC. Estudo clínico, radiográfico, microscópico e terapêutico de ameloblastomas [dissertação]. São Paulo: Universidade de São Paulo; 2008. Portuguese.

3. Curi MM, Dib LL, Pinto DS. Management of solid ameloblastoma of the jaws with liquid nitrogen spray cryosurgery. Oral Surg Oral Med Oral Pathol Oral Radiol Endod. 1997;84:339-44. http://dx.doi.org/10.1016/S10792104(97)90028-7

4. Kim SG, Jang HS. Ameloblastoma: a clinical, radiographic, and histopathologic analysis of 71 cases. Oral Surg Oral Med Oral Pathol Oral Radiol Endod. 2001;91:649-53. PMid:11402276. http://dx.doi.org/10.1067/moe.2001.114160

5. Olivati FN, Rodrigues EA, Brandão GAM, Vazquez FL, Pereira AC. Tratamento conservador e proservação de oito meses de ameloblastoma de mandíbula: relato de caso. Odonto. 2011;19:61-9. Portuguese.

6. Müller H, Slootweg P. The ameloblastoma, the controversial approach to therapy. J Maxillofac Surg. 1985;13:79-84. http:// dx.doi.org/10.1016/S0301-0503(85)80021-7

7. Yokobayashi Y, Yokobayashi T, Nakajima T, Oyama T, Fukushima M, Ishiki T. Marsupialization as a possible diagnostic aid in cystic ameloblastoma. J Maxillofac Surg. 1983;11:137-41. http://dx.doi.org/10.1016/S03010503(83)80033-2

8. Fitzgerald GWN, Frenkiel S, Black MJ, Rochon L, Baxter JD. Ameloblastomas of the jaws: a twelve year review of the McGill experience. J Otolaryngol. 1982:11:23-8. PMid:7077721.

9. Barnes L, Eveson JW, Reichart P, Sidransk D, editors. Pathology and genetics [of] head and neck tumor. Lyon: IARC; 2005. (World Health Organization Classification of Tumours).

10. Philipsen HP, Reichart PA. Unicystic ameloblastoma: a review of 193 cases from the literature. Oral Oncol. 1998;34:317-25. http://dx.doi.org/10.1016/S1368-8375(98)00012-8

11. Williams THP. Management of ameloblastoma: a changing perspective. J Oral Maxillofac Surg. 1993;51:1064-70. http:// dx.doi.org/10.1016/S0278-2391(10)80440-9

12. Rosenstein T, Pogrel MA, Smith RA, et al. Cystic ameloblastoma: behavior and treatment of 21 cases. J Oral Maxillofac Surg. 2001;59:1311-6. PMid:11688034. http://dx.doi.org/10.1053/joms.2001.27522 
13. Gold L. Biologic behavior of ameloblastoma. In: Assael LA, editor. Benign lesions of the jaws. Philadelphia: W. B. Saunders; 1991. p. 21-71.

14. Robinson L, Martinez MG. Unicystic ameloblastoma: a prognostically distinct entity. Cancer. 1977;40:2278-85. http:// dx.doi.org/10.1002/1097-0142(197711)40:5<2278::AIDCNCR2820400539>3.0.CO;2-L

15. Gardner DG. A pathologist's approach to the treatment of ameloblastoma. J Oral Maxillofac Surg. 1984;42:161-6. http://dx.doi.org/10.1016/S0278-2391(84)80026-9

16. Gomes ACA, Dias E, Gomes DO, et al. Ameloblastoma: tratamento cirúrgico conservador ou radical? Rev Cir Traumat Buco-Maxilo-Facial. 2002;2:17-24. Portuguese.

17. Bataineh $A B$. Effect of Preservation of the inferior and posterior borders on recurrence of ameloblastoma of the mandible. Oral Surg Oral Med Oral Pathol Oral Radiol Endod. 2000; 90:155-63. http://dx.doi.org/10.1067/ moe.2000.107971

18. Nakamura N, Higushi Y, Mitsuyasu T, Sandra F, Ohishi M. Comparison of long-term results between different approaches to ameloblastoma. Oral Surg Oral Med Oral Pathol Oral Radiol Endod. 2002;93:13-20. http://dx.doi.org/10.1067/ moe.2002.119517

19. Macintosh RB. Aggressive surgical management of ameloblastoma. In: Assael LA, editor. Benign Lesions of the Jaws. Philadelphia: W. B. Saunders; 1991. p. 73-97.

20. Muller H. Het ameloblastoom. Een klinish histopathologish onderzoek [thesis]. Utrecht: The Netherlands; 1983.

21. Gardner DG, Pecak AM. The treatment of ameloblastoma based on pathologic and anatomic principles. Cancer. 1980;46:2514-9. http://dx.doi. org/10.1002/1097-0142(19801201)46:11<2514::AIDCNCR2820461133>3.0.CO;2-9

22. Gortzak R, Latief B, Lekkas C, Slootweg P. Growth characteristics of large mandibular ameloblastomas: report of 5 cases with implications for the approach to surgery. Int J Oral Maxillofac Surg. 2006;35:691-5. PMid:16580817. http://dx.doi.org/10.1016/j.ijom.2006.02.013
23. Gardner DG. Some current concepts on the pathology of ameloblastomas. Oral Surg Oral Med Oral Pathol Oral Radiol Endod. 1996;82:660-9. http://dx.doi.org/10.1016/ S1079-2104(96)80441-0

24. Nakamura N, Mitsuyasu T, Higuchi Y, Sandra F, Ohishi $M$. Growth characteristics of ameloblastoma involving the alveolar nerve: a clinical and histopathologic study. Oral Surg Oral Med Oral Pathol Oral Radiol Endod. 2001;91:557-62. PMid:11346735. http://dx.doi.org/10.1067/moe.2001.113110

25. Al-Khateeb T, Ababneh KT. Ameloblastoma in young Jordanians: A review of the clinicopathologic features and treatment of 10 cases. J Oral Maxillofac Surg. 2003;61:13-8. PMid:12524602. http://dx.doi.org/10.1053/joms.2003.50002

26. Sachs SA. Surgical excision with peripheral ostectomy. A definitive yet conservative approach to the surgical management of ameloblastoma. J Oral Maxillofac Surg. 2006;64:476-83. PMid:16487812. http://dx.doi. org/10.1016/j.joms.2005.12.001

27. El Mardenly AM, El Hadidi MS. Evaluation of inferior alveolar nerve integrity in resected ameloblastic mandibular lesions. Egypt Dent J. 1989;35:183-93. PMid:2630259.

28. Wu TC, Chen Z, Tian FC, Tian QZ, You CT. Ameloblastoma of the mandible treated by resection, preservation of the inferior alveolar nerve, and bone grafting. J Oral Maxillofac Surg. 1984;42:93-6. http://dx.doi.org/10.1016/02782391(84)90318-5

29. Takahashi K, Miyauchi K, Sato K. Treatment of ameloblastoma in children. Br J Oral Maxillofac Surg.1998;36:453-6. http:// dx.doi.org/10.1016/S0266-4356(98)90462-4

30. Grempel RG, Gaião L, Souza WD, Sobreira T. Tendências de abordagens cirúrgicas no tratamen-to de ameloblastomas. Rev Bras Pat Oral. 2003;2:13-17.

31. Pizer ME, Page DG, Svirsky JA. Thirteen-year follow-up of large recurrent unicystic ameloblastoma of the mandible in a 15-year-old-boy. J Oral Maxillofac Surg. 2002;60:211-5. http://dx.doi.org/10.1053/joms.2002.29828

32. Ghandhi D, Ayoub AF, Pogrel MA, MacDonald G, Brocklebank LM, Moos KF. Ameloblastoma: a surgeon's dilemma. J Oral Maxillofac Surg. 2006;64:1010-4. PMid:16781332. http:// dx.doi.org/10.1016/j.joms.2006.03.022

\section{Conflict of interest: None}

Submitted on: $18^{\text {th }}$ August 2012

Accept on: $15^{\text {th }}$ February 2013

Correspondence: Departamento de Cirurgia e Traumatologia Bucomaxilofacial Hospital Geral Clériston Andrade - HGCA

Av. Eduardo Fróes da Mota, Bairro 35BI - Feira de Santana/BA - Brazil

CEP: 44094-000 - Phone: +55 (75) 3221-6789

E-mail: jr.odonto@gmail.com 